\title{
LETTER
}

\section{Using the lung ultrasound score to monitor disease progression for COVID-19-associated ARDS}

\author{
Maxime Nguyen ${ }^{1,2}$, Guillaume Gaujard ${ }^{1}$, Pierre-Grégoire Guinot ${ }^{1,2}$ and Belaid Bouhemad ${ }^{1,2^{*}}$ (D) on behalf of the \\ L. U. S. Study Group
}

(c) 2021 Springer-Verlag GmbH Germany, part of Springer Nature

Dear Editor,

The lung ultrasound (LUS) score identifies patients with coronavirus disease 2019 (COVID-19) and may guide triage [1]. Its monitoring and prognostic value in patients in intensive care unit (ICU) with acute respiratory distress syndrome (ARDS) needing ventilation support remains unknown.

During the first wave of the COVID-19 pandemic, we consecutively and prospectively followed 60 patients admitted for ARDS COVID-19 in our ICU. LUS score [2] was performed at admission, daily for the first-7 days and then on a 3-days' basis, since LUS examination is part of a routine monitoring of our patients. Computed tomography $(\mathrm{CT})$ scan measurement of fibrosis and ground-glass opacities (GGOs) scores [3, 4] and their changes during the ICU stay were recorded. LUS score and CT scores were compared for patients who survived and with ICU stays $\leq 14$ days (group $1, n=26$ ) and patients who died or with ICU stays $>14$ days (group $2, n=34$ ). (Table 1 ).

The LUS score at admission is higher in group $2(18 \pm 6$ vs $22 \pm 5, p<0.05)$. Bedside applicability of a difference of four in patients with high LUS score remain limited. This was showed by a receiver operating characteristic (ROC) curve area of $0.72 \pm 0.08$ (confidence interval 0.56-0.87, $p=0.012$ ) for the LUS score at admission to predict an

\footnotetext{
*Correspondence: belaid_bouhemad@hotmail.com

1 Department of Anaesthesiology and Intensive Care, CHU Dijon, BP77908, 21709 Dijon Cedex, France

Full author information is available at the end of the article
}

The members of the LUS Study Group are listed in the Acknowledgement section of the article.
ICU stay $>14$ days. However, LUS score at day 1 is correlated to the GGO score $(r=0.56, p=0.003)$ and the GGOs score was significantly higher in group $2(38 \pm 21$ vs $60 \pm 25 ; p=0.001$ ) (Table 1). No fibrosis was found in group 1 , in contrast to group 2 (fibrosis score: median $=0$ with IQR $=[0-10] ; p=0.006)$.

At day 7, LUS score remained high and was not significantly different between the both groups $(19 \pm 6$ vs $22 \pm 3, p=0.055)$. Twelve (35\%) patients died in group 2 after a median of 9 days (IQR: 13.5). Patients in group 1 left the ICU after a median stay of 7.5 days [2.3-11.8] despite the persistence of a high LUS. This underlines the discrepancy between absence of image resolution and clinical improvement. Increase of fibrosis scores can be detected using LUS only if GGOs decrease. It seems that LUS detection of fibrosis could be improved by adding quantification of pleura changes. This was recently showed in a histopathological study correlating fibroproliferative changes with a modified LUS, including a study of pleural change [5].

To summarize, our study, further clarifies the prognostic value and place of the LUS in ARDS COVID-19 patients admitted for ventilation in ICU. LUS scores is correlated with the GGO score at Day 1. However, a discrepancy between persistent high LUS score and clinical improvement was observed. Moreover, in some patients, we observed a decrease in the LUS score associated with fibroproliferative change. The severity of the included patients, may explain this discrepancy from previous triage studies [1].

\section{勿


Table 1 Main parameters

\begin{tabular}{|c|c|c|c|c|}
\hline & $\begin{array}{l}\text { Overall } \\
(n=60)\end{array}$ & $\begin{array}{l}\text { Group } 1 \\
(n=26)\end{array}$ & $\begin{array}{l}\text { Group } 2 \\
(n=34)\end{array}$ & $P$ value \\
\hline Age (years) & $62.1(11)$ & $58.6(11.9)$ & $64.7(9.63)$ & 0.037 \\
\hline Gender (male) & $35(58.3)$ & $15(57.7)$ & $20(58.8)$ & 1.000 \\
\hline BMI $\left(\mathrm{m} / \mathrm{kg}^{2}\right)$ & $29.3(5.5)$ & $30(4.9)$ & $28.8(5.9)$ & 0.390 \\
\hline \multicolumn{5}{|l|}{ Arterial blood gas at admission } \\
\hline $\mathrm{PaCO}_{2}(\mathrm{mmHg})$ & $37.6[32.8 ; 45]$ & $36.5[32.2 ; 40.4]$ & $39[35.9 ; 50.6]$ & 0.096 \\
\hline $\mathrm{P} / \mathrm{F}$ ratio & $152[121 ; 200]$ & $180[133 ; 288]$ & $142[120 ; 171]$ & 0.015 \\
\hline \multicolumn{5}{|c|}{ Invasive mechanical ventilation parameters at day 1 of ventilation } \\
\hline Number of patients & $49(81.7 \%)$ & $16(61.5 \%)$ & $33(97.1 \%)$ & 0.001 \\
\hline $\mathrm{FiO}_{2}(\%)$ & $60[50 ; 80]$ & $60[40 ; 63.8]$ & $70[60 ; 80]$ & 0.002 \\
\hline $\operatorname{PEEP}\left(\mathrm{cmH}_{2} \mathrm{O}\right)$ & $12[10.8 ; 13.2]$ & $12[12 ; 12.2]$ & $12[10 ; 14]$ & 0.991 \\
\hline Pplat $\left(\mathrm{cmH}_{2} \mathrm{O}\right)$ & $23.7(3.4)$ & $23.9(2.9)$ & $23.5(3.7)$ & 0.731 \\
\hline Tidal volume (ml) & $386(67.5)$ & $388(40.6)$ & $384(80.2)$ & 0.853 \\
\hline Norepinephrine & $36(60)$ & $10(38.5)$ & $26(76.5)$ & 0.007 \\
\hline Dose ( $\mu \mathrm{g} / \mathrm{kg} / \mathrm{min})$ & $0.04[0 ; 0.17]$ & $0[0 ; 0.09]$ & $0.1[0.01 ; 0.25]$ & 0.003 \\
\hline LUS score at day 1 & $20 \pm 5$ & $18 \pm 6$ & $22 \pm 5$ & 0.013 \\
\hline LUS score at day 7 & $21 \pm 5$ & $19 \pm 6$ & $22 \pm 3$ & 0.14 \\
\hline \multicolumn{5}{|l|}{ CT scan at admission } \\
\hline Ground-glass opacity score & $60[30 ; 70]$ & $40[20 ; 60]$ & $65[33 ; 80]$ & 0.002 \\
\hline Fibrosis score & $0[0 ; 0]$ & $0[0 ; 0]$ & $0[0 ; 10]$ & 0.006 \\
\hline \multicolumn{5}{|l|}{ Outcome } \\
\hline ICU stay (days) & $15[6.8 ; 26.2]$ & $7.5[2.3 ; 11.8]$ & $23.5[19 ; 32.8]$ & $<0.001$ \\
\hline Duration of mechanical ventilation (days) & $13.5[4.8 ; 23]$ & $3.5[0 ; 8.8]$ & $21.5[16.2 ; 28.5]$ & $<0.001$ \\
\hline
\end{tabular}

Numbers are given as mean $( \pm S D)$, median [IQR], number (\%). Group 1: surviving patients with an ICU stay $\leq 14$ days; group 2: deceased patients or patients with an $\mathrm{ICU}$ stay $>14$ days. Comparisons between groups were made using the Mann-Whitney $\mathrm{U}$ and $\mathrm{Chi}$-squared tests for continuous and categorical variables. $P / \mathrm{F} \mathrm{PaO} \mathrm{P}_{2} /$ $\mathrm{FiO}_{2}$ ratio, PEEP positive end expiratory pressure, Pplat plateau pressure. CT scan at admission were available in 21 (81\%) patients of group 1 and 29 (82\%) patients for group 2

\section{Supplementary Information}

The online version contains supplementary material available at https://doi. org/10.1007/s00134-021-06515-x.

\section{Author details}

1 Department of Anaesthesiology and Intensive Care, CHU Dijon, BP77908, 21709 Dijon Cedex, France. ${ }^{2}$ Université Bourgogne Franche-Comté, LNC UMR1231, 21000 Dijon, France.

\section{Acknowledgements}

The LUS Study Group members are Erminio Santangelo: Department of Anaesthesiology and Intensive Care, CHU Dijon, BP77908, 21709 Dijon Cedex, France; Fabien Robelin: Department of Radiology, CHU Dijon, BP77908, 21709 Dijon Cedex, France; Ophélie Dransart-Rayé: Department of Anaesthesiology and Intensive Care, CHU Dijon, BP77908, 21709 Dijon Cedex, France; Nicolas Nowobilski: Department of Anaesthesiology and Intensive Care, CHU Dijon, BP77908, 21709 Dijon Cedex, France; Frederic Ricolfi: Department of Radiology, CHU Dijon, BP77908, 21709 Dijon Cedex, France; Francesco Mojoli: Department of Anaesthesia and Intensive Care, Istituto di Ricovero e Cura a Carattere Scientifico, Policlinico San Matteo Foundation, Pavia, Italy; Silvia Mongodi: Department of Anaesthesia and Intensive Care, Istituto di Ricovero e Cura a Carattere Scientifico, Policlinico San Matteo Foundation, Pavia, Italy.

\section{Author contributions}

$\mathrm{BB}, \mathrm{MN}$ and P-GG contributed to the study concept and design; performed the data collection and analysis, and drafted the manuscript. GG performed the data collection. All the members of the study contributed in data collection, analysis and/or revising the manuscript.

\section{Funding}

Support was provided solely from institutional and/or departmental sources (Service d'Anesthésie Réanimation CHU Dijon, BP 77908, 21709 Dijon Cedex, France).

\section{Declarations}

\section{Conflicts of interest}

On behalf of all authors, the corresponding author states that there is no conflict of interest.

\section{Ethical approval}

In accordance with the law on personal data protection of 6 January 1978 (number 78-17), our study was submitted to the National Commission of Data Protection (CNIL) via the hospital's personal data protection correspondent (declaration number 2013053v0)

\section{Informed consent}

Observational study for whom written consent was waived according to French law (Law 88-1138 of 20 December 1988, modified on 9 August 2004, on biomedical research). Patients received an information concerning study, their right to refuse to participate in the study and their right to withdraw at any time.

\section{Publisher's Note}

Springer Nature remains neutral with regard to jurisdictional claims in published maps and institutional affiliations. 
Received: 1 June 2021 Accepted: 24 August 2021

Published online: 30 September 2021

\section{References}

1. Zieleskiewicz L, Markarian T, Lopez A, Taguet C, Mohammedi N, Boucekine M, Baumstarck K, Besch G, Mathon G, Duclos G, Bouvet L, Michelet P, Allaouchiche B, Chaumoitre K, Di Bisceglie M, Leone M, Network A (2020) Comparative study of lung ultrasound and chest computed tomography scan in the assessment of severity of confirmed COVID-19 pneumonia. Intensive Care Med 46:1707-1713

2. Bouhemad B, Brisson H, Le-Guen M, Arbelot C, Lu Q, Rouby JJ (2011) Bedside ultrasound assessment of positive end-expiratory pressure-induced lung recruitment. Am J Respir Crit Care Med 183:341-347
3. Jung Jl, Kim HH, Jung YJ, Park SH, Lee JM, Hahn ST (2000) Mediastinal lymphadenopathy in pulmonary fibrosis: correlation with disease severity. J Comput Assist Tomogr 24:706-710

4. Wagner M, Chang Chien KC, Aidara O, Fetita C, Brauner MW, Nunes $H$, Valeyre D, Brillet PY (2011) CT imaging of chronic interstitial lung diseases: from diagnosis to automated quantification. Rev Mal Respir 28:1207-1215

5. de Almeida Monteiro RA, Duarte-Neto AN, da Silva LFF, de Oliveira EP, de Nascimento ECT, Mauad T, Saldiva P, Dolhnikoff M (2021) Ultrasound assessment of pulmonary fibroproliferative changes in severe COVID-19: a quantitative correlation study with histopathological findings. Intensive Care Med 47:199-207 